\title{
PCSK9 siRNA suppresses the inflammatory response induced by oxLDL through inhibition of NF-kB activation in THP-1-derived macrophages
}

\author{
ZHIHAN TANG $^{1 *}$, LU JIANG ${ }^{1 *}$, JUAN PENG $^{1}$, ZHONG REN $^{1}$, DANGHENG WEI ${ }^{1}$, \\ CHUNYANG WU ${ }^{1}$, LIHONG PAN ${ }^{2}$, ZHISHENG JIANG ${ }^{1}$ and LUSHAN LIU ${ }^{1}$ \\ ${ }^{1}$ Institute of Cardiovascular Disease, Key Laboratory for Arteriosclerology of Hunan Province, ${ }^{2}$ Department of Neurology, \\ The Second Affiliated Hospital, University of South China, Hengyang, Hunan 421001, P.R. China
}

Received April 5, 2012; Accepted May 29, 2012

DOI: $10.3892 /$ ijmm.2012.1072

\begin{abstract}
Proprotein convertase subtilisin/kexin 9 (PCSK9), a member of the protein-converting enzyme family, is highly expressed in adult hepatocytes and small intestinal enterocytes. To our knowledge, in this study, we demonstrate for the first time that PCSK9 is upregulated in a dose-dependent manner via oxidized low-density lipoprotein (oxLDL) stimulation in THP-1-derived macrophages. PCSK9 small interfering RNA (siRNA) suppresses the oxLDL-induced inflammatory cytokine expression in THP-1-derived macrophages. The exposure of macrophages to oxLDL markedly increased the expression of $\mathrm{NF}-\kappa \mathrm{B}$ protein in the nucleus. However, this effect was significantly attenuated by PCSK 9 siRNA. These findings indicate that PCSK9 expression is induced by oxLDL, and that PCSK9 siRNA protects against inflammation via the inhibition of NF- $\kappa \mathrm{B}$ activation in oxLDL-stimulated THP-1derived macrophages. Our results suggest that PCSK9 may be used as a therapeutic target for the treatment of atherosclerosis since PCSK 9 siRNA suppresses oxLDL-induced I $\kappa$ B- $\alpha$ degradation and $\mathrm{NF}-\kappa \mathrm{B}$ nuclear translocation into THP-1-derived macrophages.
\end{abstract}

\section{Introduction}

Proprotein convertase subtilisin/kexin 9 (PCSK9), a member of the protein-converting enzyme family, is highly expressed in

Correspondence to: Dr Zhisheng Jiang or Professor Lushan Liu, Institute of Cardiovascular Disease, Key Laboratory for Arteriosclerology of Hunan Province, University of South China, 28 West Changsheng Road, Hengyang, Hunan 421001, P.R. China

E-mail: zsjiang2005@163.com

E-mail: liulushan@yahoo.cn

*Contributed equally

Key words: proprotein convertase subtilisin/kexin type 9, macrophages, oxidized low-density lipoprotein, small interfering RNA, inflammatory cytokine adult hepatocytes and small intestinal enterocytes (1). PCSK9 is found to be related to autosomal dominant hypercholesterolemia $(2,3)$. Recent studies have revealed that PCSK9 plays a unique role in the control of plasma low-density lipoprotein cholesterol (LDL-C) levels by regulating LDL receptor (LDLR) in the hepatocyte cell membrane (4-6). Thus, PCSK9 has emerged as a new target for the treatment of dyslipidemia $(7,8)$. Certain studies have shown that PCSK9 may regulate neuronal apoptosis and affect the nervous system differentiation. These data support a novel role for PCSK9 in central nervous system (CNS) development, different from that in cholesterogenic organs (9). Therefore, PCSK9 may have biological activities beyond LDLR homeostasis. A recent in vivo study revealed that infection and inflammation stimulate PCSK9 expression (10). Lan et al (11) used microarray analysis to identify possible genome-wide gene expression and pathway alterations in HepG2 cells treated with wild-type or D374Y gain-of-function PCSK9 proteins. They identified novel pathways that are presumably regulated by PCSK9 and are independent of its effects on cholesterol uptake. These pathways are involved in protein ubiquitination, xenobiotic metabolism, cell cycle and inflammation and stress responses. Both the upregulation and downregulation of genes in the inflammation and stress response pathway were also observed in their study.

Atherosclerosis is a vascular disease, characterized by chronic inflammation of the arterial wall (12). Previous studies have proposed that the inflammatory response of macrophages induced by oxidized LDL (oxLDL) is a key event in the pathogenesis of atherosclerosis $(13,14)$. Previously, we found that PCSK9 is involved in the apoptosis of human umbilical vein endothelial cells (HUVECs) induced by oxLDL (15). We also showed that PCSK9 is expressed in THP-1-derived macrophages and in New Zealand rabbit atherosclerotic lesion foam cells (16).

The effect of PCSK9 on the inflammatory response of macrophages induced by oxLDL remains unknown. The present study indicates that PCSK9 affects the biological effect induced by oxLDL in THP-1-derived macrophages. Therefore, we used THP-1-derived macrophages to examine the effect of oxLDL on PCSK9 expression. The role of PCSK9 in the oxLDL-induced inflammatory response of these macrophages 
Table I. siRNAs and PCR primers used in this study.

\begin{tabular}{|c|c|c|c|}
\hline Name & & Primer sequences & Products \\
\hline \multirow[t]{2}{*}{ PCSK9 siRNA } & Sense & 5'-GGCAGAGACUGAUCCACUUdTdT-3' & \\
\hline & Antisense & 3'-dTdTCCGUCUCUGACUAGGUGAA-5' & \\
\hline \multirow[t]{2}{*}{ PCSK9 } & Forward & 5'-ACGATGCCTGCCTCTACTCC-3' & 205 bp \\
\hline & Reverse & 5'-GCCTGTGATGTCCCACTCTGT-3' & \\
\hline \multirow{2}{*}{$\mathrm{IL}-1 \alpha$} & Forward & 5'-AGTAGCAACCAACGGGAA-3' & 374 bp \\
\hline & Reverse & 5'-CATCTTGGGCAGTCACATA-3' & \\
\hline \multirow[t]{2}{*}{ IL-6 } & Forward & 5'-ACATTTGCCGAAGAGCC-3' & 234 bp \\
\hline & Reverse & 5'-GTAGTGAGGAACAAGCCAGAG-3' & \\
\hline \multirow[t]{2}{*}{ TNF- $\alpha$} & Forward & 5'-CTGCCTGCTGCACTTTGGAG-3' & 348 bp \\
\hline & Reverse & 5'-TGGTAGGAGACGGCGATGC-3' & \\
\hline \multirow{2}{*}{ GAPDH } & Forward & 5'-CAAGGTCATCCATGACAACTTTG-3' & 496 bp \\
\hline & Reverse & 5'-GTCCACCACCCTGTTGCTGTAG-3' & \\
\hline
\end{tabular}

was examined using small interfering RNA (siRNA) to knockdown PCSK9 expression.

\section{Materials and methods}

Cell culture and treatments. THP-1 cells were purchased from the Cell Center of the Institute of Biochemistry and Cell Biology, Shanghai, China. Cells grown in a monolayer were maintained in RPMI-1640 medium containing $10 \%$ fetal bovine serum and $10 \mathrm{mM}$ HEPES at $37^{\circ} \mathrm{C}$ in $5 \% \mathrm{CO}_{2}$. The cells were induced to differentiate into macrophages by adding $160 \mathrm{nM}$ phorbol 12-myristate 13-acetate and incubated for $24 \mathrm{~h}$. Healthy human plasma was purchased from the Hengyang Blood Center. Native LDL was separated via ultracentrifugation, oxidized using $10 \mu \mathrm{M} \mathrm{CuSO}_{4}$, and then stored at $4^{\circ} \mathrm{C}$. Agarose $(0.5 \%)$ gel electrophoresis was used to verify the oxidation of the native LDL. THP-1-derived macrophages were incubated with various concentrations of oxLDL $(10-80 \mu \mathrm{g} / \mathrm{ml})$ under different time courses $(6-24 \mathrm{~h})$ to examine the expression levels of IL-1 $\alpha$, IL-6, TNF- $\alpha$ and PCSK9.

siRNA transfection. PCSK9 siRNA was designed based on the PCSK9 mRNA sequence (GenBank, no. NM_174936) and synthesized by Guangzhou Biotechnology Co., Guangzhou, China. Sequences of the PCSK9 siRNA sense and antisense strands are presented in Table I. The negative control siRNA was provided by the same company. The PCSK9 siRNA was diluted in Opti-MEM I and added to the culture medium at a final concentration of 20,40 or $80 \mathrm{nM}$. The transfection of siRNA into THP-1-derived macrophages in suspension was conducted using Lipofectamine 2000 according to the manufacturer's instructions (Invitrogen, Carlsbad, CA, USA). To select the most effective siRNA concentration, reverse transcription-polymerase chain reaction (RT-PCR) and western blot analysis were performed $24 \mathrm{~h}$ after transfection. The concentrations of PCSK9 siRNA for maximal effects were used to conduct the following experiments.

Cytokine enzyme-linked immunosorbent assay (ELISA). Cells were plated in 6-well plates and treated as mentioned above. Culture supernatants were collected and stored at $-20^{\circ} \mathrm{C}$ until analysis. The concentrations of IL-1 $\alpha$, IL- 6 and TNF- $\alpha$ in the supernatants were measured using ELISA (DuoSet ELISA Development System; R\&D Systems, Abingdon, UK) following the manufacturer's instructions. The cytokine standards were used to generate standard curves. Quantitative determinations in 3 different experiments were performed.

$R T-P C R$. Total RNA was extracted from the cells using TRIzol reagent in accordance with the manufacturer's instructions. Specific PCR primers for human PCSK9, IL-1 $\alpha$, IL-6, and TNF- $\alpha$ are presented in Table I. RT-PCR products were analyzed via $1.2 \%$ agarose gel electrophoresis and a UVP gel image analysis system.

Western blot analysis. Total, cytoplasmic and nuclear protein were extracted from the cells using the Nuclear and Cytoplasmic Protein Extraction kit (Auragene Bioscience, Changsha, China) according to the manufacturer's instructions. The protein concentration was determined using the bicinchoninic acid method. The samples were analyzed by western blot analysis using $10 \%$ sodium dodecyl sulfate-polyacrylamide gel electrophoresis, and then transferred to a polyvinylidene fluoride membrane. Subsequently, the membrane was blocked in TBST $(20 \mathrm{mM}$ Tris base $\mathrm{pH} 7.6,150 \mathrm{mM} \mathrm{NaCl}, 0.1 \%$ Tween-20) containing 5\% non-fat milk for $4 \mathrm{~h}$ at room temperature. Antibodies against

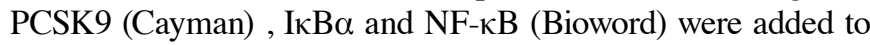
the blocking solution, and the membrane was incubated at $4^{\circ} \mathrm{C}$ overnight. After the overnight incubation, the membrane was washed 3 times with TBST for $30 \mathrm{~min}$, and then incubated with the horseradish peroxidase-conjugated anti-rabbit immunoglobulin $\mathrm{G}$ antibodies (Zhongshan Golden Bridge Inc., Beijing, China) for an additional $50 \mathrm{~min}$ at room temperature. Finally, the membrane was washed 3 times with TBST for $30 \mathrm{~min}$. Immunoreactivity was detected using enhanced chemiluminescence. Signal intensities were quantified via densitometry using Labwords analysis software.

Statistical analysis. Data are expressed as the means \pm SEM. The results were analyzed using one-way analysis of variance 
A

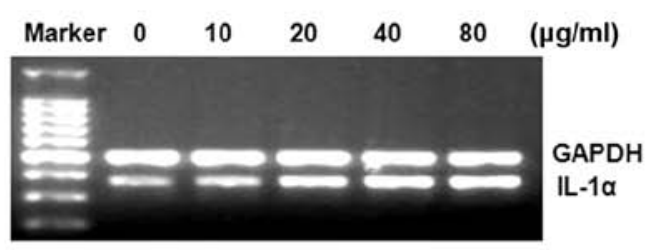

$\begin{array}{lllllll}\text { Marker } & 0 & 10 & 20 & 40 & 80 & (\mu \mathrm{g} / \mathrm{ml})\end{array}$
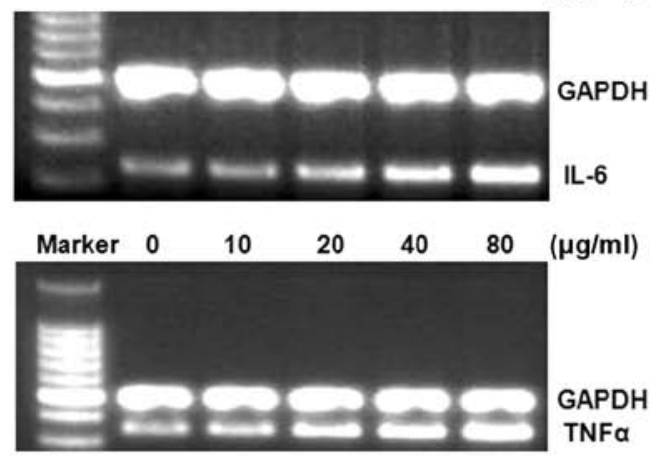

D
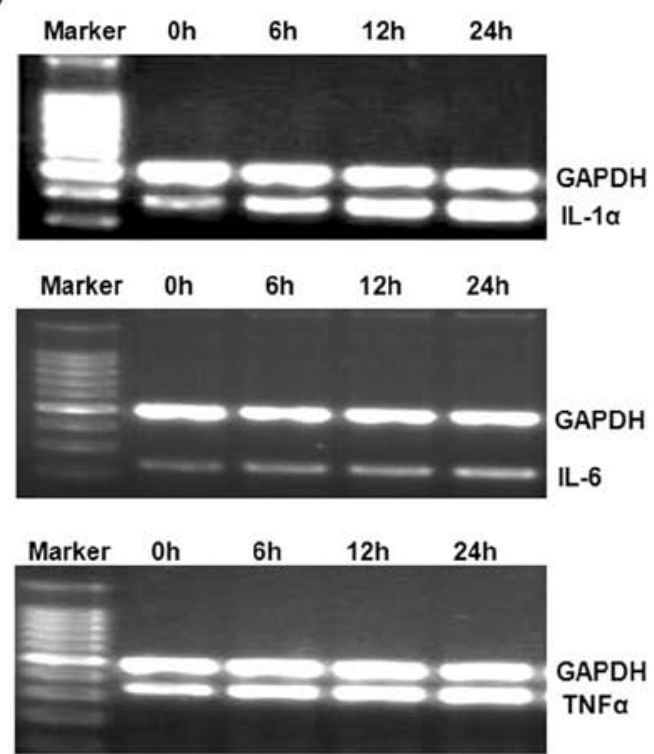

B

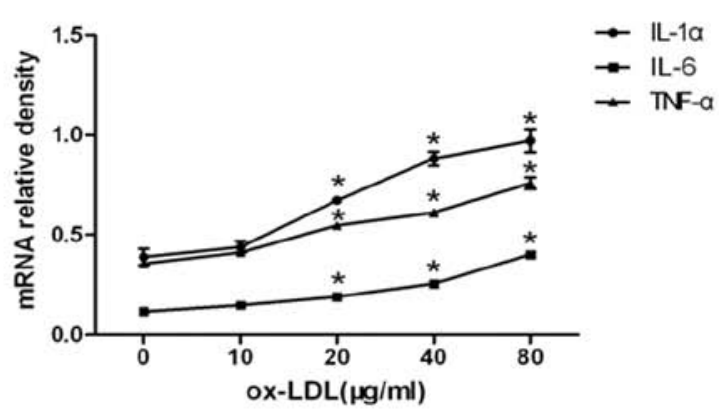

C

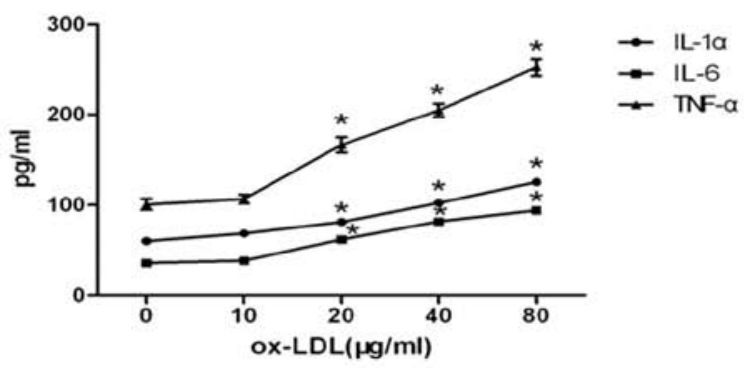

E

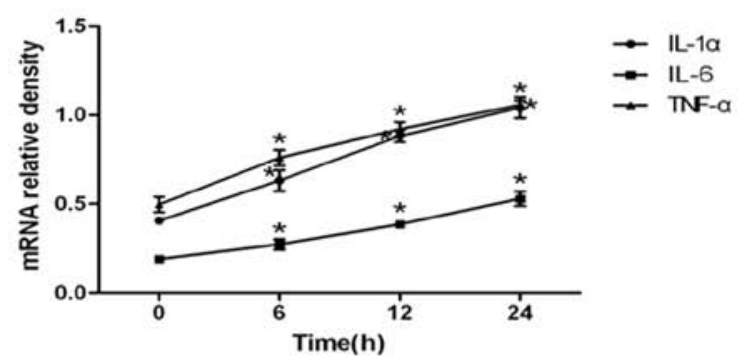

$\mathbf{F}$

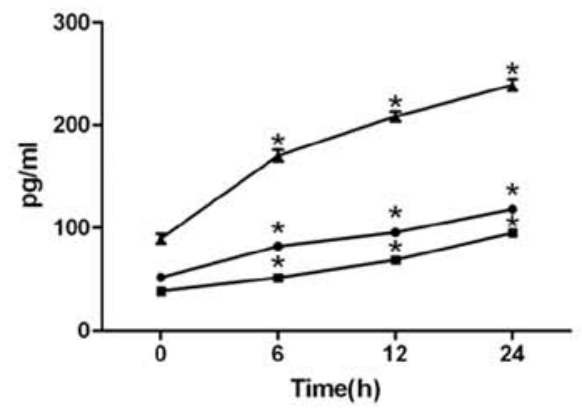

$\rightarrow \mathrm{IL}-1 \mathrm{a}$

$\rightarrow \mathrm{IL}-6$

$+\mathrm{TNF}-\mathrm{a}$

Figure 1. OxLDL upregulated the mRNA expression and secretion of inflammatory cytokines in THP-1-derived macrophages in a dose- and time-dependent manner. (A-C) THP-1-derived macrophages were treated with increasing concentrations of oxLDL for $24 \mathrm{~h}$. (A and B) After incubation, the mRNA expression of the cells was analyzed with RT-PCR. (C) Concentrations of IL- $1 \alpha$, IL-6 and TNF- $\alpha$ were measured using ELISA ("P $<0.05$, compared with $0 \mu \mathrm{g} / \mathrm{ml}$ oxLDL). (D-F) THP-1-derived macrophages were treated with $80 \mu \mathrm{g} / \mathrm{ml}$ oxLDL for various amounts of time. (D and E) The mRNA expression of L-1 $\alpha$, IL-6 and TNF- $\alpha$ was determined by RT-PCR. (F) Protein secretion levels of IL- $1 \alpha$, IL- 6 and TNF- $\alpha$ were measured using ELISA ("P<0.05 compared with 0 h). All results are expressed as the means \pm SEM from 3 independent experiments.

(ANOVA), the Student's t-test and SPSS 13.0 software. $\mathrm{P}<0.05$ was considered to indicate a statistically significant difference.

\section{Results}

OxLDL upregulates the $M R N A$ expression and secretion of inflammatory cytokines in a dose- and time-dependent manner. To determine whether oxLDL affects the synthesis and secretion of IL- $1 \alpha$, IL- 6 and TNF- $\alpha$, the 3 inflammatory mediators involved in atherosclerosis, THP-1-derived macro- phages were treated with various doses of $\operatorname{oxLDL}(0,10,20$, 40 and $80 \mu \mathrm{g} / \mathrm{ml}$ ) for $24 \mathrm{~h}$. Total-RNAs were extracted and analyzed for the mRNA expression levels of these cytokines using RT-PCR. As shown in Fig. 1A and B, oxLDL increased the amounts of IL- $1 \alpha$, IL- 6 and TNF- $\alpha$ mRNA in a dosedependent manner. The amounts of IL-1 $\alpha$, IL- 6 and TNF- $\alpha$ secreted from the cells were determined by ELISA (Fig. 1C). oxLDL increased the amounts of IL- $1 \alpha$, IL- 6 and TNF- $\alpha$ in a dose-dependent manner. These results suggest that oxLDL upregulates both the mRNA expression and secretion of inflammatory cytokines in a dose-dependent manner. 
A

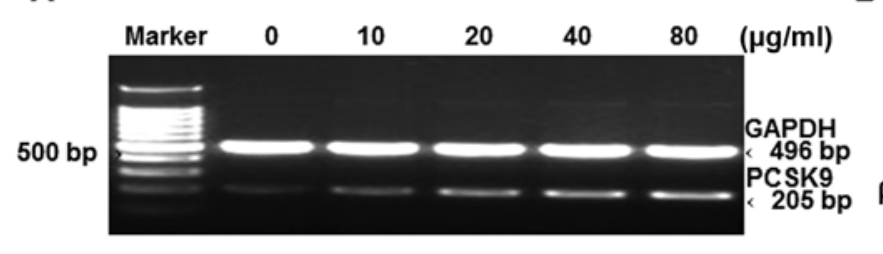

B

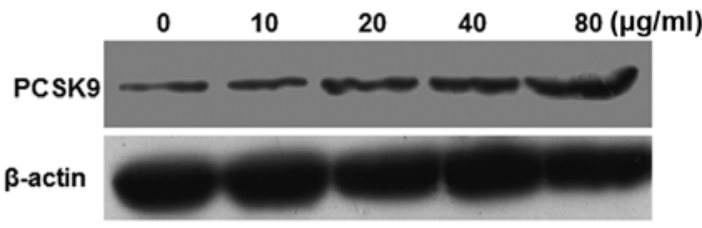

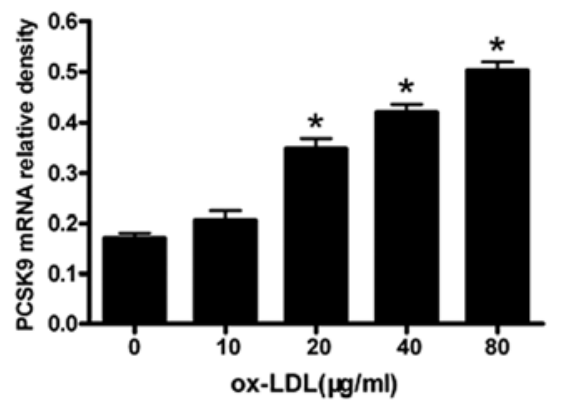

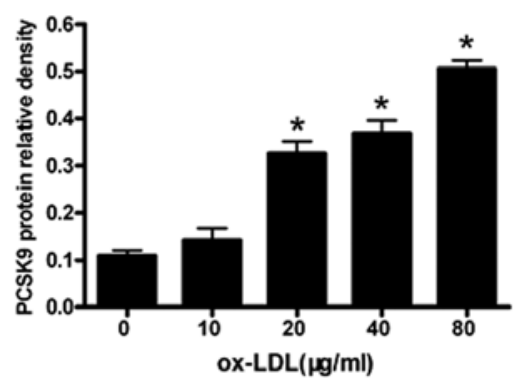

Figure 2. OxLDL upregulated PCSK9 expression in THP-1-derived macrophages in a dose-dependent manner. (A) Cells were treated with 0, 10, 20, 40 and $80 \mu \mathrm{g} / \mathrm{ml}$ oxLDL for $24 \mathrm{~h}$. Total RNA was extracted, and RT-PCR was performed to determine the level of PCSK9 mRNA. (B) Cells were treated with 0 , 10 , 20,40 and $80 \mu \mathrm{g} / \mathrm{ml}$ for $24 \mathrm{~h}$. PCSK9 protein levels were measured by western blot analyses. All results are expressed as the means \pm SEM from 3 independent experiments, each performed in triplicate ( $\mathrm{P}<0.05 \mathrm{vs} .0 \mu \mathrm{g} / \mathrm{ml}$ oxLDL).

Experiments were also performed to determine the time course of the oxLDL-induced upregulation in IL-1 $\alpha$, IL-6 and TNF- $\alpha$ mRNA levels and the amounts of IL- $1 \alpha$, IL-6 and TNF- $\alpha$ secreted from the cells (Fig. 1D and E). oxLDL increased the levels of IL- $1 \alpha$, IL- 6 and TNF- $\alpha$ mRNA in a timedependent manner. This upregulation also led to increases in the amounts of IL- $1 \alpha$, IL- 6 and TNF- $\alpha$ secreted into the culture medium (Fig. 1F). Our results suggest that OxLDL upregulates the mRNA expression and secretion of inflammatory cytokines in a dose-and time-dependent manner (Fig. 1).

OxLDL upregulates PCSK9 expression in THP-1-derived macrophages in a dose-dependent manner. We then investigated whether the expression of PCSK9 in THP-1-derived macrophages is affected by oxLDL stimulation. THP-1derived macrophages were treated with oxLDL $(0,10,20$, 40 and $80 \mu \mathrm{g} / \mathrm{ml}$ ) for $24 \mathrm{~h}$. The levels of PCSK9 mRNA and protein were measured using RT-PCR and western blot analysis, respectively. The expression of PCSK9 mRNA and protein were upregulated in a concentration-dependent manner $(\mathrm{P}<0.05)$ (Fig. 2), with the highest expression of PCSK9 resulting from treatments of $80 \mu \mathrm{g} / \mathrm{ml}$ oxLDL $(\mathrm{P}<0.05)$. These results suggest that oxLDL upregulates the PCSK9 expression in THP-1-derived macrophages in a dose-dependent manner.

PCSK9 siRNA reduces the expression of PCSK9 in THP-1derived macrophages. THP-1-derived macrophages were transfected with various concentrations of siRNA $(20,40$ and $80 \mathrm{nM}$ ) for $24 \mathrm{~h}$. The total-RNAs and proteins were extracted. PCSK 9 mRNA was detected by RT-PCR. The treatment with $80 \mathrm{nM}$ PCSK9 siRNA significantly knocked down the expression of the PCSK9 gene (Fig. 3A). Western blot analysis showed that PCSK9 protein levels were reduced in PCSK9 siRNA-transfected cells when compared with cells transfected with the siRNA controls $(\mathrm{P}<0.05)$ (Fig. 3B).
Therefore, $80 \mathrm{nM}$ PCSK9 siRNA was used in the subsequent experiments.

PCSK9 siRNA suppresses the oxLDL-induced upregulation of $I L-1 \alpha, I L-6$ and TNF- $\alpha$ in THP-1-derived macrophages. We then investigated whether transfection with PCSK9 siRNA can regulate the inflammatory response in oxLDL-activated macrophages. THP-1-derived macrophages were transfected with the control siRNA or PCSK 9 siRNA $(80 \mathrm{nM})$, cultured for $24 \mathrm{~h}$ in medium, and then treated with oxLDL $(80 \mu \mathrm{g} / \mathrm{ml})$ for $24 \mathrm{~h}$. First, we examined the mRNA expression of IL-1 $\alpha$, IL-6 and TNF- $\alpha$ in oxLDL-induced macrophages. PCSK9 siRNA significantly reduced oxLDL-induced mRNA expression of IL-1 $\alpha$, IL- 6 and TNF- $\alpha$, as determined by RT- PCR (Fig. 4A and B). The concentrations of IL-1 $\alpha$, IL- 6 and TNF- $\alpha$ in the medium were further determined by ELISA. Consistently, the results showed that PCSK9 siRNA suppressed the oxLDLinduced upregulation of IL-1 $\alpha$, IL-6 and TNF- $\alpha$ (Fig. 4C). These results suggest that PCSK9 siRNA suppresses the oxLDL-induced upregulation of IL- $1 \alpha$, IL- 6 and TNF- $\alpha$ in THP-1-derived macrophages.

PCSK9 siRNA suppresses ox LDL-induced I $\kappa$ - $\alpha$ degradation and NF- $\kappa B$ nuclear translocation in THP-1-derived macrophages. $\mathrm{NF}-\kappa \mathrm{B}$ is a major transcription factor regulating the induction of various inflammatory mediators. To elucidate the molecular mechanism underlying the anti-inflammatory effects of PCSK9 siRNA in THP-1-derived macrophages, we further investigated the effect of PCSK9 siRNA on the NF- $\kappa$ B activity in THP-1-derived macrophages treated with or without oxLDL. Following cellular stimulation with oxLDL, IкB- $\alpha$ (a protein inhibiting the translocation of $\mathrm{NF}-\kappa \mathrm{B}$ into the nucleus) was degraded significantly in macrophages (Fig. 5A). The levels of NF- $\kappa$ B p 65 protein in the nucleus were significantly increased in the cells treated with oxLDL (Fig. 5B). By contrast, PCSK9 

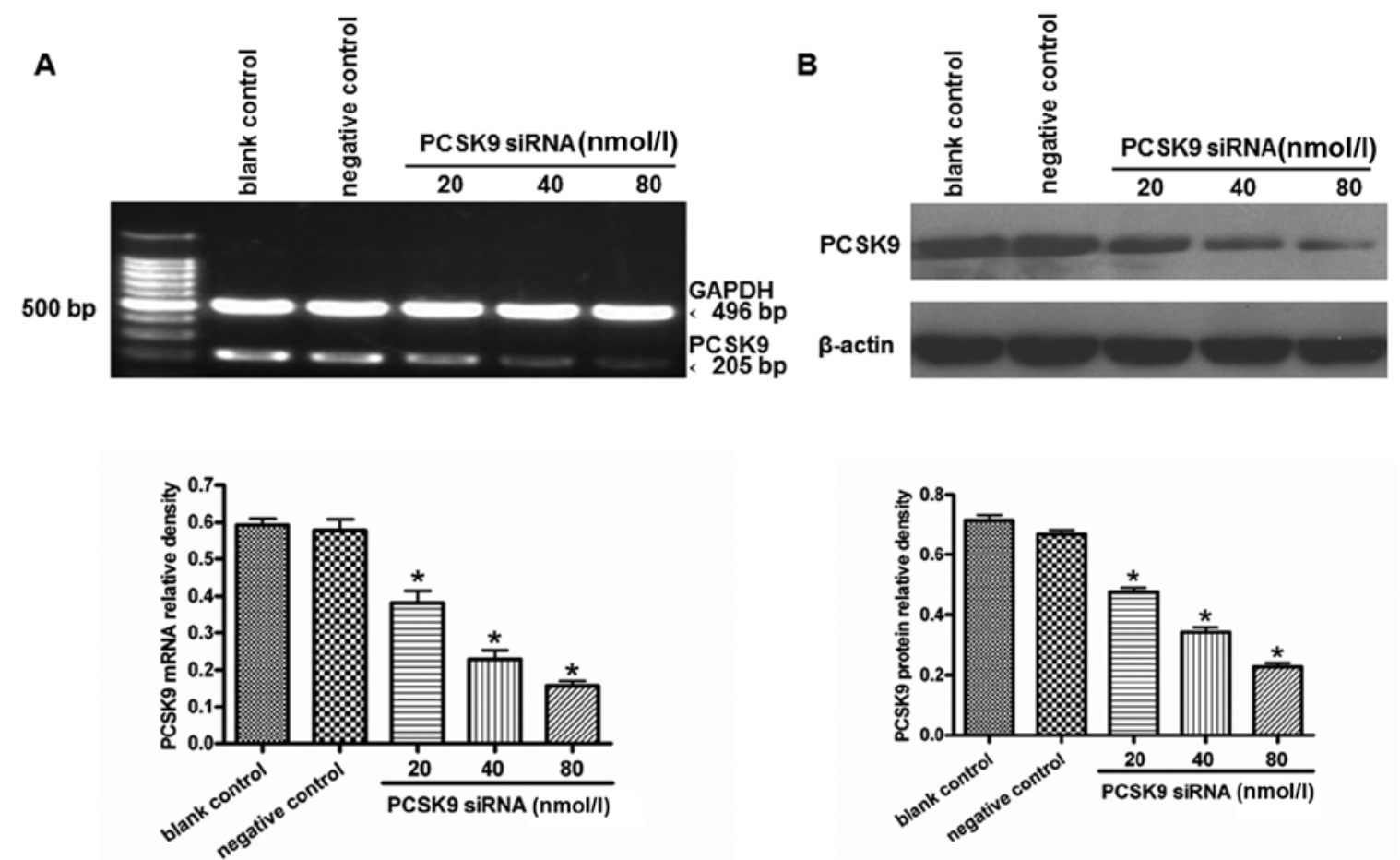

Figure 3. PCSK9 siRNA reduced the expression of PCSK9 in THP-1-derived macrophages. (A) THP-1-derived macrophages were transfected with 20,40 and $80 \mathrm{nM}$ siRNA for $24 \mathrm{~h}$, and PCSK9 mRNA was then detected by RT-PCR. (B) Cells were treated with 20, 40 and $80 \mathrm{nM}$ siRNA for $24 \mathrm{~h}$. Western blot analyses were performed to examine the PCSK9 protein expression. All results are expressed as the means \pm SEM from 3 independent experiments ("P<0.05 vs. blank control).

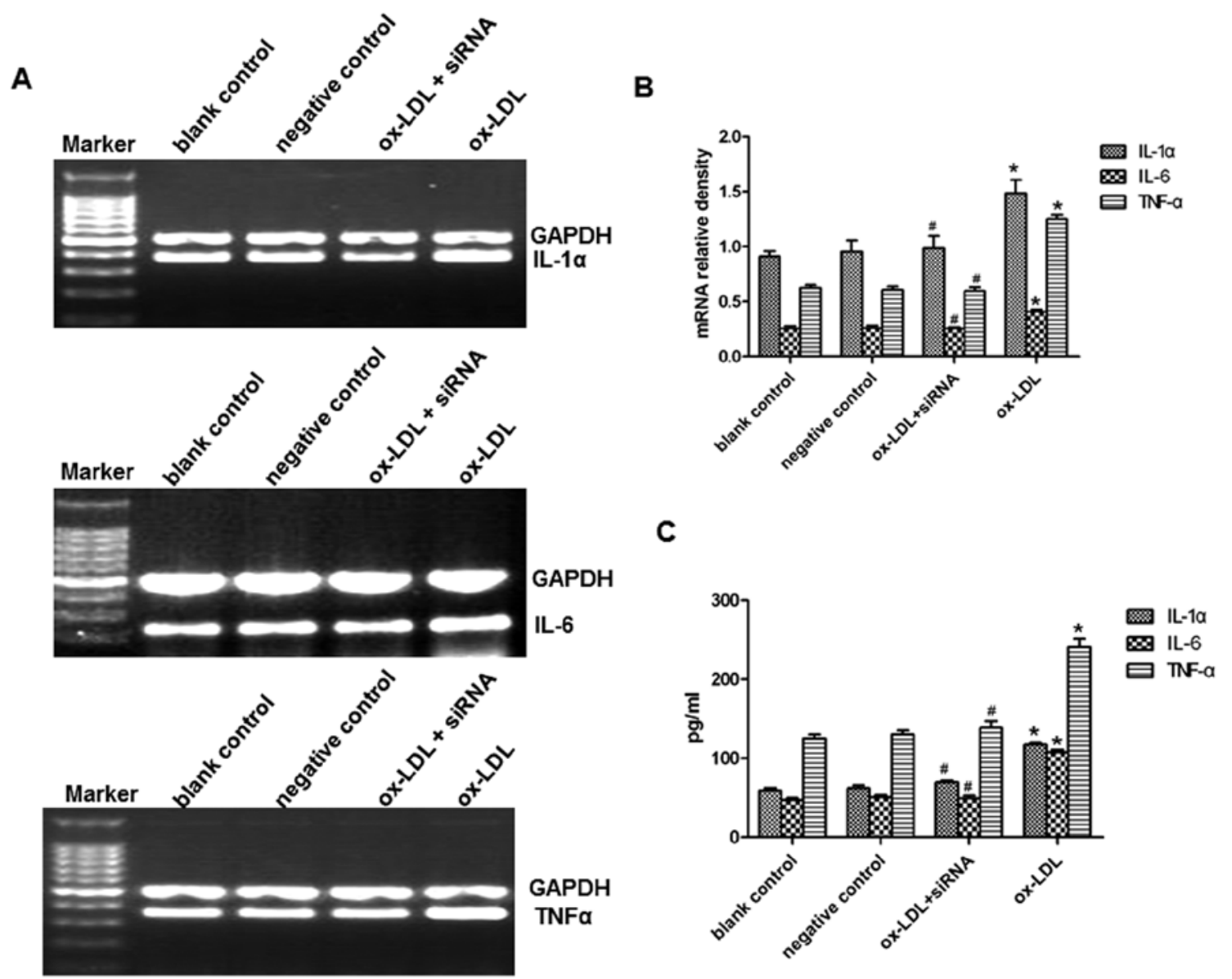

Figure 4. PCSK9 siRNA suppressed the oxLDL-induced upregulation of IL-1 $\alpha$, IL-6 and TNF- $\alpha$ in THP-1-derived macrophages. THP-1-derived macrophages transfected with $80 \mathrm{nM}$ PCSK9 siRNA were treated with $80 \mu \mathrm{g} / \mathrm{ml}$ oxLDL for $24 \mathrm{~h}$. (A and B) The mRNA expression of IL-1 $\alpha$, IL-6 and TNF- $\alpha$ was determined by RT-PCR ("P<0.05 vs. blank control, ${ }^{*} \mathrm{P}<0.05$ vs. oxLDL). (C) IL-1 $\alpha$, IL-6 and TNF- $\alpha$ proteins were detected using ELISA ("P $<0.05$ vs. blank control; ${ }^{*} \mathrm{P}<0.05$ vs. oxLDL). All results are expressed as the means \pm SEM from 3 independent experiments. 

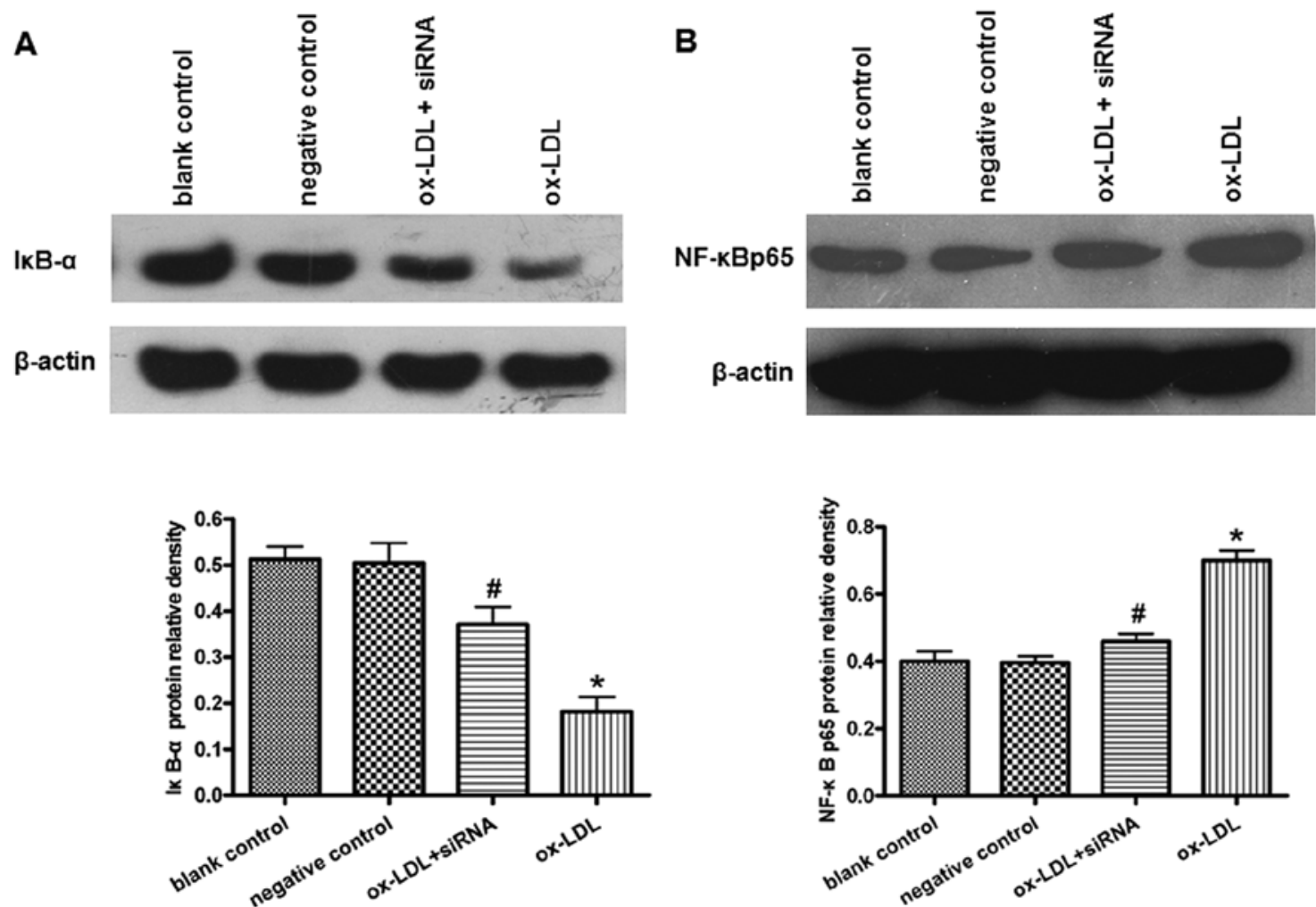

Figure 5. PCSK9 siRNA suppressed oxLDL-induced IкB- $\alpha$ degradation and NF-кB p65 nuclear translocation into THP-1-derived macrophages. After transfection with $80 \mathrm{nmol} / 1$ PCSK9 siRNA, THP-1-derived macrophages were treated with $80 \mu \mathrm{g} / \mathrm{ml}$ oxLDL for $24 \mathrm{~h}$. (A) The protein levels of cytoplasmic IкB- $\alpha$ were detected by western blot analyses ( $\left(\mathrm{P}<0.05\right.$ vs. blank control; ${ }^{*} \mathrm{P}<0.05 \mathrm{vs}$. oxLDL). (B) Western blot analysis was used to measure the levels of the nuclear NF- $\kappa B$ p 65 protein $\left({ }^{*} \mathrm{P}<0.05\right.$ vs. blank control; ${ }^{*} \mathrm{P}<0.05$ vs. oxLDL). All results are expressed as the means \pm SEM from 3 independent experiments.

siRNA partially suppressed the degradation of I $\kappa \mathrm{B}-\alpha$ and the nuclear translocation of NF- $\kappa \mathrm{B}$ p65 (P<0.05) (Fig. 5).

\section{Discussion}

Atherosclerosis is generally considered a pathological process caused by hyperlipidemia. Recently, atherosclerosis was found to be a chronic inflammatory response process beyond lipid metabolism disturbance (17). Many genes related to lipid metabolism or inflammation are involved in the pathogenesis of atherosclerosis, such as LDLR, apolipoprotein E (ApoE), C-reactive protein (CRP) and TNF- $\alpha$ (18). Ma et al (19) investigated the effects of inflammatory stress on cholesterol accumulation in the liver and revealed the correlation between lipid metabolism and inflammatory response. ATP-binding membrane cassette transporter A1 has been found to be a possible link between inflammation and reverse cholesterol transport $(20,21)$. Much attention has been focused on genes that play important roles in both lipid metabolism and inflammatory response.

PCSK9 is a secreted glycoprotein that regulates the degradation of LDLR. The function of PCSK9 is currently focused on lipid metabolism regulation (22-24). Gain-of-function PCSK9 mutations cause hypercholesterolemia and coronary heart disease (CHD) $(25,26)$. Loss-of-function PCSK9 mutations decrease LDL levels and reduce CHD $(27,28)$. As shown in a previous study, PCSK9-deficient mice exhibited impaired glucose tolerance and pancreatic islet abnormalities (29). Langhi et al (30) showed that PCSK9 does not alter insulin secretion, although PCSK9 is expressed in pancreatic $\delta$ cells. Previously, to our knowledge, we reported for the first time that oxLDL-induced HUVEC THP-1-derived macrophage apoptosis is effectively inhibited by PCSK9 siRNA via the Bcl/ Bax-caspase-9-3 pathway (15). We also found that PCSK9 is expressed in THP-1-derived macrophages and New Zealand rabbit atherosclerotic lesion macrophages (16). PCSK9 is markedly induced by diverse inflammatory stimuli, such as lipopolysaccharide, zymosan and turpentine (10). PCSK9 may be a key regulator in lipid metabolism, inflammation, and atherosclerosis.

Considering that oxLDL is a major pro-inflammatory factor in the development of atherosclerosis, we selected oxLDL-stimulated THP-1-derived macrophages as the cell model. In the present study, IL-1 $\alpha$, IL- 6 and TNF- $\alpha$ expression and secretion increased with oxLDL in a dose- and time-dependent manner. Importantly, oxLDL also increased the PCSK9 expression in THP-1-derived macrophages in a dose-dependent manner. The change in the PCSK9 expression is consistent with the change in inflammatory cytokine secretion in the oxLDL-stimulated THP-1-derived macrophages.

Subsequently, we investigated the role of PCSK9 in oxLDLinduced inflammatory response in THP-1-derived macrophages using RNA interference. In the present study, we used 3 siRNA concentrations (20,40 and $80 \mathrm{nM}$ ) and found that the silencing effect was more potent with increasing concentrations of siRNA, as detected at both the mRNA and protein levels. The final siRNA concentration of $80 \mathrm{nM}$ showed the most dramatic silencing effects. Therefore, we used $80 \mathrm{nM}$ PCSK9 siRNA 
in all subsequent experiments. The cells were transfected with PCSK9 siRNA, cultured for $24 \mathrm{~h}$, and then exposed to oxLDL for $24 \mathrm{~h}$. The expression and secretion of inflammatory cytokines were determined. Compared to the cells incubated with oxLDL only, PCSK9 siRNA significantly suppressed the expression and secretion of IL- $1 \alpha$, IL- 6 and TNF- $\alpha$. These results further suggest that PCSK9 is involved in the regulation of the oxLDL-induced inflammatory response in THP-1-derived macrophages.

Therefore, we attempted to identify the detailed mechanism of PCSK9 siRNA in regulating the inflammatory response. $\mathrm{NF}-\kappa \mathrm{B}$ is a critical transcriptional regulator of a number of genes involved in immune and inflammatory responses (31). In the resting state, $\mathrm{NF}-\kappa \mathrm{B}$ is sequestered in the cytoplasm by binding to an inhibitory factor, I $\kappa \mathrm{B} \alpha$. With cell stimulation, I $\kappa \mathrm{B} \alpha$ is phosphorylated and degraded. Unbound NF- $\kappa \mathrm{B}$ is then released and translocated into the nucleus where it activates the transcription of target genes, such as cytokines, chemokines, adhesion molecules and apoptosis inhibitors $(32,33)$. $\mathrm{NF}-\kappa \mathrm{B}$ activation also plays a key role in the oxLDL-induced expression of inflammatory cytokines in macrophages (34-35). Thus, we speculate that the suppression of pro-inflammation cytokine secretion by PCSK9 siRNA is related with NF- $\kappa \mathrm{B}$ activation. In the present study, the results suggest that PCSK9 siRNA reduces the degradation of $\mathrm{I} \kappa \mathrm{B} \alpha$ and suppresses the nuclear translocation of NF- $\mathrm{B}$ p65 induced by oxLDL in macrophages, indicating that the NF- $\kappa \mathrm{B}$ activation is inhibited by PCSK 9 siRNA. Collectively, PCSK 9 siRNA suppresses not only the IL- $1 \alpha$, IL- 6 and TNF- $\alpha$ expression and secretion but also $\mathrm{NF}-\kappa \mathrm{B}$ activation. Further, the activation of $\mathrm{NF}-\kappa \mathrm{B}$ is responsible for inflammatory cytokine expression and secretion. Therefore, in oxLDL-stimulated macrophages, the inhibitory effect of PCSK9 siRNA on inflammatory cytokines expression and secretion is partly associated with the downregulation of the $\mathrm{NF}-\kappa \mathrm{B}$ activation.

In conclusion, to our knowledge, the results of the present study strongly indicate for the first time that PCSK9 may be induced in THP-1-derived macrophages in response to oxLDL. We also demonstrate that PCSK9 siRNA suppresses the oxLDL-induced pro-inflammatory cytokine synthesis and secretion by inhibiting $\mathrm{NF}-\kappa \mathrm{B}$ translocation into the nucleus, which exhibits an anti-inflammatory role in macrophages. We believe that further clarifying the functional role of PCSK9 will hasten its application as a unique aid for atherosclerosis therapeutic targets.

\section{Acknowledgements}

This study was supported by grants from the Key Project of Educational Department of Hunan Province (10A105), the Project of Science and Technology Department of Hunan Province (2009TP4057-2, 2010TP4008-2), and the Project of Health Department of Hunan Province (B2011-042), and by the Aid Program for Science and Technology Innovative Research Team in Higher Educational Institutions of Hunan Province.

\section{References}

1. Cariou B, Le May C and Costet P: Clinical aspects of PCSK9. Atherosclerosis 216: 258-265, 2011.
2. Maxwell KN, Soccio RE, Duncan EM, Sehayek E and Breslow JL: Novel putative SREBP and LXR target genes identified by microarray analysis in liver of cholesterol-fed mice. J Lipid Res 44: 2109-2119, 2003.

3. Seidah NG, Benjannet S, Wickham L, et al: The secretory proprotein convertase neural apoptosis-regulated convertase 1 (NARC-1): liver regeneration and neuronal differentiation. Proc Natl Acad Sci USA 100: 928-933, 2003.

4. Yamamoto T, Lu C and Ryan RO: A two-step binding model of PCSK9 interaction with the low density lipoprotein receptor. J Biol Chem 286: 5464-5470, 2011.

5. Davignon J, Dubuc G and Seidah NG: The influence of PCSK9 polymorphisms on serum low-density lipoprotein cholesterol and risk of atherosclerosis. Curr Atheroscler Rep 12: 308-315, 2010.

6. Mousavi SA, Berge KE and Leren TP: The unique role of proprotein convertase subtilisin/kexin 9 in cholesterol homeostasis. J Intern Med 266: 507-519, 2009.

7. Marian AJ: PCSK9 as a therapeutic target in atherosclerosis. Curr Atheroscler Rep 12: 151-154, 2010.

8. Duff CJ and Hooper NM: PCSK9: an emerging target for treatment of hypercholesterolemia. Expert Opin Ther Targets 15: 157-168, 2011.

9. Poirier S, Prat A, Marcinkiewicz E, et al: Implication of the proprotein convertase NARC-1/PCSK9 in the development of the nervous system. J Neurochem 98: 838-850, 2006.

10. Feingold KR, Moser AH, Shigenaga JK, Patzek SM and Grunfeld C: Inflammation stimulates the expression of PCSK9. Biochem Biophys Res Commun 374: 341-344, 2008.

11. Lan H, Pang L, Smith MM, et al: Proprotein convertase subtilisin/kexin type 9 (PCSK9) affects gene expression pathways beyond cholesterol metabolism in liver cells. J Cell Physiol 224: 273-281, 2010.

12. Ross R: Atherosclerosis is an inflammatory disease. Am Heart J 138: S419-S420, 1999.

13. Rodriguez G, Mago N and Rosa F: Role of inflammation in atherogenesis. Invest Clin 50: 109-129, 2009.

14. Saha P, Modarai B, Humphries J, Mattock K, Waltham M, Burnand KG and Smith A: The monocyte/macrophage as a therapeutic target in atherosclerosis. Curr Opin Pharmacol 9: 109-118, 2009.

15. Wu CY, Tang ZH, Jiang L, Li XF, Jiang ZS and Liu LS: PCSK9 siRNA inhibits HUVEC apoptosis induced by ox-LDL via Bcl/Bax-caspase9-caspase3 pathway. Mol Cell Biochem 359: 347-358, 2012.

16. Tang ZH, Liu LS, Peng J, Yang Q, Liu HT and Jiang ZS: Investigation of NARC-1 protein expression in atherosclerotic lesion of New Zealand rabbit. Chin J Arterioscler 17: 35-37, 2009 (in Chinese).

17. Libby P, Okamoto $\mathrm{Y}$, Rocha $\mathrm{VZ}$ and Folco E: Inflammation in atherosclerosis: transition from theory to practice. Circ J 74: 213-220, 2010.

18. Yin $\mathrm{K}$ and Tang $\mathrm{C}$ : Inflammation, lipid metabolism dysfunction, and hypertension: Active research fields in atherosclerosisrelated cardiovascular disease in China. Sci China Life Sci 54: 976-979, 2011.

19. Ma KL, Ruan XZ, Powis SH, Chen Y, Moorhead JF and Varghese Z: Inflammatory stress exacerbates lipid accumulation in hepatic cells and fatty livers of apolipoprotein E knockout mice. Hepatology 48: 770-781, 2008.

20. Yin K, Liao DF and Tang CK: ATP-binding membrane cassette transporter A1 (ABCA1): a possible link between inflammation and reverse cholesterol transport. Mol Med 16: 438-449, 2010.

21. Yin K, Deng X, Mo ZC, et al: Tristetraprolin-dependent post-transcriptional regulation of inflammatory cytokine mRNA expression by apolipoprotein A-I: role of ATP-binding membrane cassette transporter A1 and signal transducer and activator of transcription 3. J Biol Chem 286: 13834-13845, 2011.

22. Roubtsova A, Munkonda MN, Awan Z, et al: Circulating proprotein convertase subtilisin/kexin 9 (PCSK9) regulates VLDLR protein and triglyceride accumulation in visceral adipose tissue. Arterioscler Thromb Vasc Biol 31: 785-791, 2011.

23. Holla OL, Cameron J, Tveten K, Strom TB, Berge KE, Laerdahl JK and Leren TP: Role of the C-terminal domain of PCSK9 in degradation of the LDL receptors. J Lipid Res 52: 1787-1794, 2011.

24. Soutar AK: Unexpected roles for PCSK9 in lipid metabolism. Curr Opin Lipidol 22: 192-196, 2011. 
25. Fisher TS, Lo Surdo P, Pandit S, et al: Effects of $\mathrm{pH}$ and low density lipoprotein (LDL) on PCSK9-dependent LDL receptor regulation. J Biol Chem 282: 20502-20512, 2007.

26. Cunningham D, Danley DE, Geoghegan KF, et al: Structural and biophysical studies of PCSK9 and its mutants linked to familial hypercholesterolemia. Nat Struct Mol Biol 14: 413-419, 2007.

27. Zhang DW, Lagace TA, Garuti R, Zhao Z, McDonald M, Horton JD, Cohen JC and Hobbs HH: Binding of proprotein convertase subtilisin/kexin type 9 to epidermal growth factorlike repeat $\mathrm{A}$ of low density lipoprotein receptor decreases receptor recycling and increases degradation. J Biol Chem 282: 18602-18612, 2007.

28. Cameron J, Holla OL, Ranheim T, Kulseth MA, Berge KE and Leren TP: Effect of mutations in the PCSK9 gene on the cell surface LDL receptors. Hum Mol Genet 15: 1551-1558, 2006.

29. Mbikay M, Sirois F, Mayne J, et al: PCSK9-deficient mice exhibit impaired glucose tolerance and pancreatic islet abnormalities. FEBS Lett 584: 701-706, 2010.

30. Langhi C, Le May C, Gmyr V, et al: PCSK9 is expressed in pancreatic delta-cells and does not alter insulin secretion. Biochem Biophys Res Commun 390: 1288-1293, 2009.
31. De Bosscher K, Vanden BW and Haegeman G: The interplay between the glucocorticoid receptor and nuclear factor-kappaB or activator protein-1: molecular mechanisms for gene repression. Endocr Rev 24: 488-522, 2003.

32. Gloire G, Legrand-Poels S and Piette J: NF-kappaB activation by reactive oxygen species: fifteen years later. Biochem Pharmacol 72: 1493-1505, 2006.

33. de Winther MP, Kanters E, Kraal G and Hofker MH: Nuclear factor kappaB signaling in atherogenesis. Arterioscler Thromb Vasc Biol 25: 904-914, 2005.

34. Xie C, Kang J, Ferguson ME, Nagarajan S, Badger TM and Wu X: Blueberries reduce pro-inflammatory cytokine TNF- $\alpha$ and IL- 6 production in mouse macrophages by inhibiting $\mathrm{NF}-\kappa \mathrm{B}$ activation and the MAPK pathway. Mol Nutr Food Res 55: 1587-1591, 2011

35. Lei L, Li H, Yan F, Li Y and Xiao Y: Porphyromonas gingivalis lipopolysaccharide alters atherosclerotic-related gene expression in oxidized low-density-lipoprotein-induced macrophages and foam cells. J Periodontal Res 46: 427-437, 2011. 